\title{
High-Index Immersion Fluids Enabling Cost-Effective Single- Exposure Lithography For 32 nm Half Pitches
}

\author{
Roger H. French ${ }^{\mathrm{a}}$, Hoang V. Tran ${ }^{\mathrm{a}}$, Doug J. Adelman ${ }^{\mathrm{a}}$, Nyrissa S. Rogado ${ }^{\mathrm{a}}$, \\ Mureo Kaku ${ }^{\mathrm{b}}$, Michael Mocella ${ }^{\mathrm{c}}$, Charles Y. Chen ${ }^{\mathrm{d}}$ Eric Hendrickx ${ }^{\mathrm{e}}$, \\ Frieda Van Roey ${ }^{\mathrm{e}}$, Adam S. Bernfeld ${ }^{\mathrm{a}}$, Rebekah A. Derryberry ${ }^{\mathrm{a}}$ \\ ${ }^{\mathrm{a}}$ DuPont Co. Central Research, Wilmington DE, 19880-0400 \\ ${ }^{b}$ DuPont K. K., NBD-J, Utsunomiya-shi, Japan 321-3231 \\ ${ }^{\mathrm{c}}$ DuPont Co., Electronic Technologies, Wilmington DE, 19880-0030 \\ ${ }^{\mathrm{d}}$ DuPont-EKC, Hayward CA, 94545 \\ 'IMEC, Kapeldreef 75, B3001 Leuven, Belgium
}

\begin{abstract}
We have performed high-index immersion fluid studies to define the levels of both soluble and insoluble impurities present. These studies have also revealed the importance of process materials' purity in fluid contact. Fluid interactions with resist, leading to both surface and imaging defects, can be minimized by proper resist selection. Our Active Recycle Package technology can greatly extend the useful life of both the fluid itself, as well as the final lens element.
\end{abstract}

Keywords: immersion, second generation fluid, hydrocarbons, refractive index, absorbance, fluid handling, radiation durability, active recycle, window contamination, particle contamination

\section{INTRODUCTION}

Without precedent in industry history, three distinct lithographic technologies are now being readied for manufacturing insertion in the foreseeable (1-7 years) future. These technologies - water immersion double patterning, high-index immersion (in both single-exposure and double-patterning variations) and EUV - are commonly considered competing technologies. Although there is some limited merit in this view, these technologies are actually best viewed as complementary, and so mutually supporting to achieve the industry's overall technology goals.

Thus (Figure 1), water-based immersion lithography's emergence enabled half-pitch resolutions to below $40 \mathrm{~nm}$, a level not achievable by dry $193 \mathrm{~nm}$ illumination methods, and so extended the utility of the current leading-edge imaging wavelength. By adopting methods such as the various double-patterning options, this approach could extend to perhaps $26 \mathrm{~nm}$ or even less - meeting the most-demanding near-term user requirements for memory technologies in particular. These water-immersion extensions have allowed more time for the other two technologies to develop; at present, highindex immersion is the next technology likely to insert. In this way, the aggressive $\mathrm{k}_{1}$ values needed for water double patterning can be relaxed, giving more process latitude. At the same time, returning to a single-exposure method is expected to provide the cost and throughput advantages which are generally obtained versus a double-patterning approach.

The next patterning approach is presently unclear. If EUV is ready with acceptable CoO, it would be inserted due to the extendibility advantages it offers versus the other two approaches. However, the multiple unresolved technical issues in EUV - including notably tool development, an illumination source of sufficient power, a mature mask production and inspection infrastructure, and photoresists with acceptable combinations of sensitivity and resolution - suggest that interim approaches will be required. In such a case, the experience gained in double-patterning approaches with water can form the basis for similar high-index methods, enabling half pitches approaching $16 \mathrm{~nm}$ to be realized with the most

- Contact: *roger.h.french@usa.dupont.com 
aggressive $\mathrm{k}_{1}$ reductions. In this way, the full EUV infrastructure can develop over a period more suitable for the major process and materials shifts which accompany any patterning wavelength change.

To support these transitions, we are continuing our work to develop the fluid and associated technologies for high-index immersion, to ensure their readiness as needed in the full set of lithographic options. ${ }^{1,2,3,4,5,6,7}$ We report here on selected aspects of this ongoing work, including high-index fluid issues comprising quality, handling, and resist interaction concerns; and radiation durability and fluid recycle technology advances..

\section{FLUID QUALITY AND HANDLING}

\subsection{Particles and Residues}

Our efforts continue on the elimination of both soluble and insoluble impurities, to obtain ultrapure highindex liquids. For example, during testing to find the most compatible and efficient filters for IF132 (our leading high-index immersion fluid candidate), we have found that filters vary in their ability to remove insoluble particles, and that some add additional soluble contaminants. Some of these soluble contaminants do not reduce fluid transparency at $193 \mathrm{~nm}$, so we have focused on droplet and misting tests to determine the filtered fluids' cleanliness.

Residue analysis tests involved manually dispensing droplets (1-5 $\mathrm{mm}$ in diameter) onto prewashed bare Si wafers, then monitoring the droplets' room temperature evaporation in a clean room environment with a LEXT confocal microscope. IF132 droplets in this size range require hours to completely evaporate at room temperature; therefore, evaporation was accelerated by heating the wafers until the droplets were $\sim 500 \mu \mathrm{m}$ in diameter, and further evaporation was then monitored at room temperature. Residues were counted, their areas tabulated, and the final residue volume percent calculated based on the initial droplet volume. The details of this analysis method are significant, and so are included here.

A sessile droplet's volume on a wafer is determined using Equation 1, where Figure 2 shows the relevant sessile droplet parameters: radius $\mathrm{r}$, height $\mathrm{h}$, and contact angle $\theta$.

$$
\text { Equation 1. } V=\frac{1}{6} \pi \tan \theta\left(3+\tan ^{2} \theta\right) r^{3}
$$

To determine the fluid's residue volume fraction, the residues were analyzed using an Olympus LEXT OLS 3100 (Olympus Surgical and Industrial America Inc, Micro-Imaging Division, One Corporate Drive, Orangeburg, NY 10962) and the LEXT OLS software. Projected residue areas on a wafer are generated for each individual residue using the LEXT analySIS software; the projected residue area A corresponds to the radius, $r$, of a sessile droplet as shown in Equation 2.

$$
\text { Equation 2. } \quad r^{2}=\frac{A}{\pi}
$$

Substituting Equation 2 into Equation 1, the volume of a single residue can be found using Equation 3.

$$
\text { Equation 3. } \quad V=\frac{1}{6} \pi \tan \theta\left(3+\tan ^{2} \theta\right)\left(\frac{A}{\pi}\right)^{3 / 2}
$$

The volume fraction $\mathrm{V} \%$ of all residues present in a fluid sessile droplet is found by dividing the summed residue volumes $V_{R}$, by the initial sessile droplet volume $V$, as shown in Equation 4.

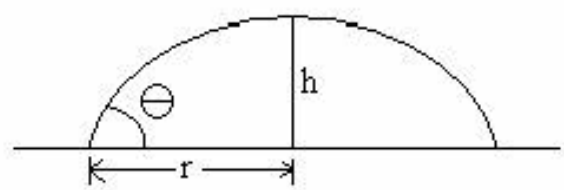

Figure 2. Diagram of a cross-section of a droplet/dome showing height, $h$, radius, r. and contact angle. $\theta$ 


$$
\text { Equation 4. } V \%=\frac{\sum_{i} V_{R, i}}{V}
$$

Residue volume fractions are calculated using Equation 5 , assuming the same contact angles for the residues and the initial fluid droplet, and substituting Equation 1 and Equation 3 into Equation 4 for the initial sessile droplet volume $\mathrm{V}$, and the residue volumes $\mathrm{V}_{\mathrm{R}, \mathrm{i}}$, respectively.

Equation 5. $\quad V \%=\frac{\sum_{i}\left(A_{i}^{3 / 2}\right)}{r^{3} \pi^{3 / 2}}$

In Equation 5, $\mathrm{A}_{\mathrm{i}}$ is the individual projected areas of the residues detected and $\mathrm{r}$ is the radius of the initial sessile droplet.

Figure 3 shows the final image of an IF132 droplet evaporated on a bare $\mathrm{Si}$ wafer for about 15 minutes, compared to the same fluid that was first filtered through a Whatman PTFE $0.45 \mu \mathrm{m}$ filter. The initial fluid showed a calculated $100 \mathrm{ppb}$ residue, while the filtered droplet corresponded to more than $1 \mathrm{ppm}$ residue. Figure 4 shows the initial fluid's absorbance spectrum, compared to those filtered through two filter types. As can be seen, materials of construction such as filters can not only introduce particles and insoluble residues, but may also add soluble contaminants which increase fluid absorbance. Therefore, it is important to select materials which minimize fluid contamination, and also to implement an active recycle technology to remove these contaminants. Of course, the active recycle technology must also control use-generated contaminants, such as those from fluid contact with the resist and/or topcoat, and fluid degradation products resulting from $193 \mathrm{~nm}$ illumination.

\section{FLUID-RESIST INTERACTIONS}

Building on previous studies ${ }^{8}$ of high index fluid/resist interactions - in particular the Sumitomo PAR-817 resist we now have additional data on a water-specific immersion resist, TOK TArF-Pi6-001. Misting experiments were performed to test both initial fluid cleanliness on bare $\mathrm{Si}$ wafers, as well as additional defects upon direct fluid-resist contact. PAG leaching into both water and two high index fluids were compared between the two resists. Finally, tests were performed to compare the fluids' effects on CD variation in pre-exposure and post-exposure soak modes on wafers patterned with both resists (a)

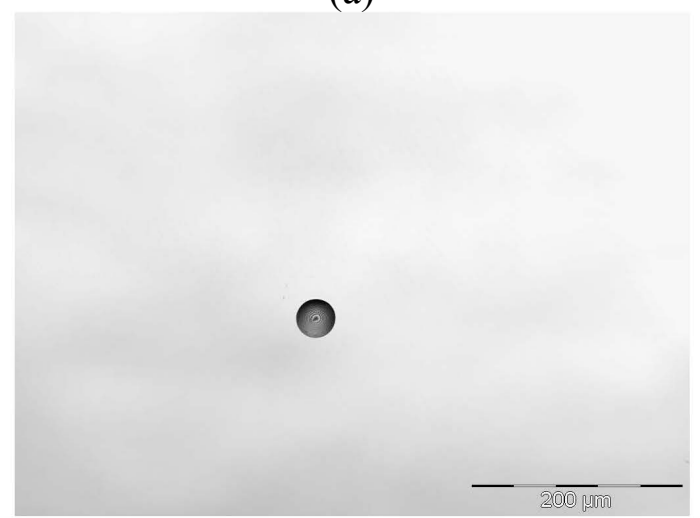

(b)

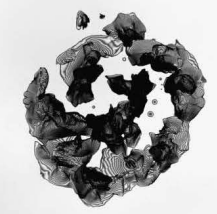

Figure 3. Final confocal image of an IF132 droplet (a) evaporated on a bare Si wafer for 15 minutes, compared to (b) a droplet of IF132 that has been filtered through a Whatman PTFE $0.45 \mu \mathrm{m}$ filter.

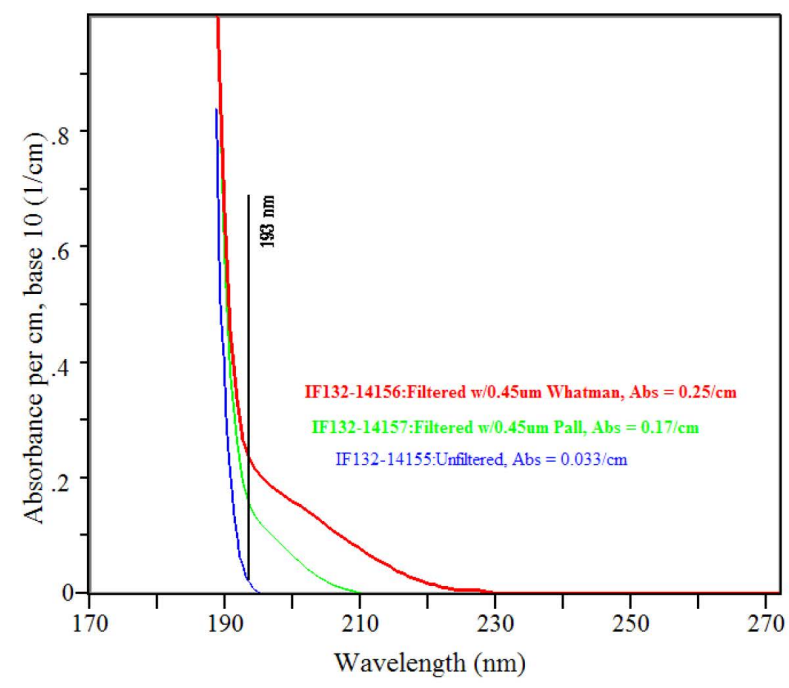

Figure 4. Absorbance of clean, unfiltered fluid compared to fluid that has been filtered through two types of filters. 


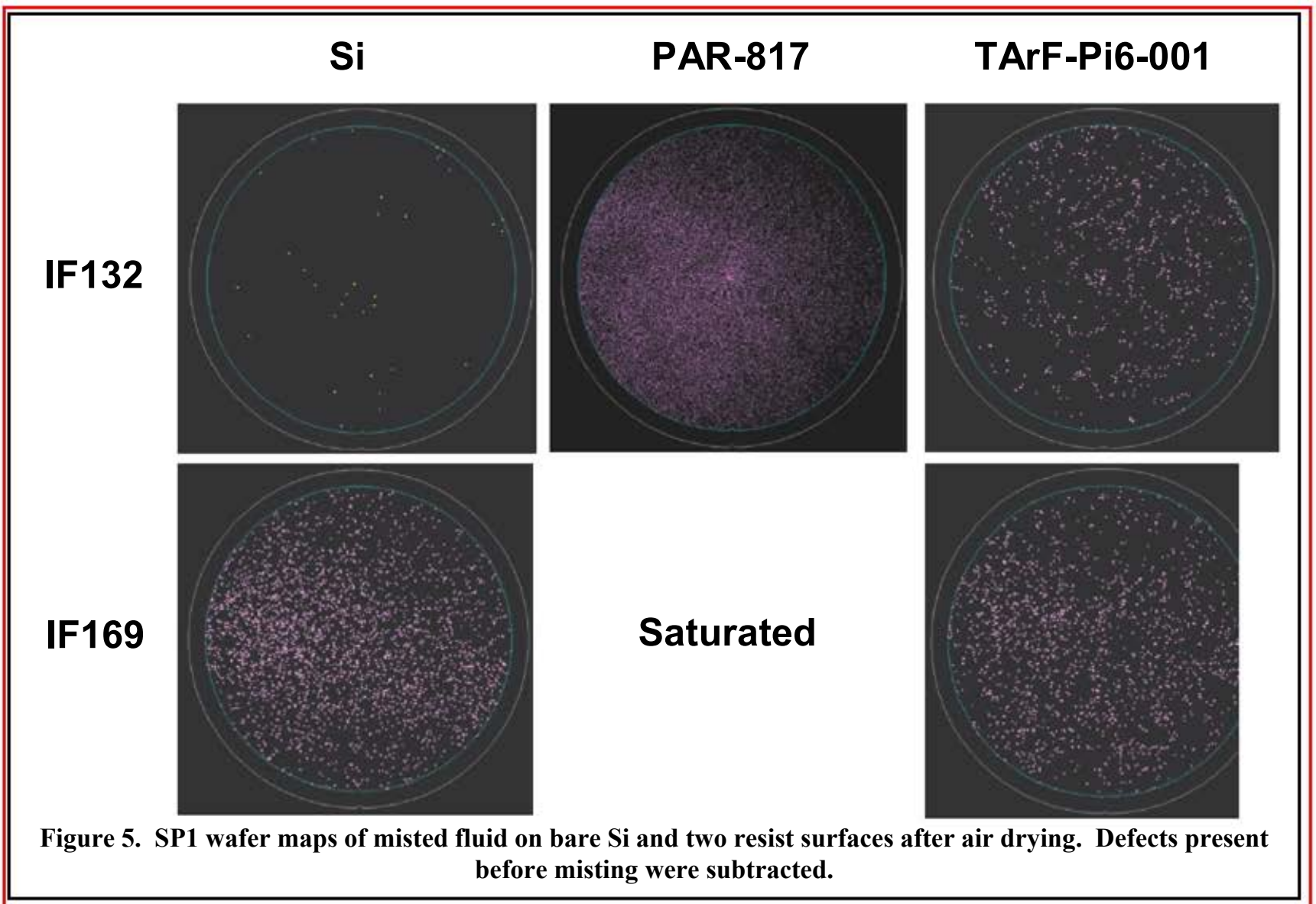

\subsection{Misting Defectivity}

A glass reagent sprayer (CAMAG) was used to mist thousands of high index fluid droplets onto bare $\mathrm{Si}$ wafers and resist-coated wafers. The droplets were air dried, and defects measured on a KLA SP1 Surfscan defect inspection tool. Defects present before misting were subtracted. A control experiment was also performed to test the sprayer's cleanliness, where a blank Si wafer was sprayed only with air; about 50 added defects (the base background level) were found. Note that we found the defect counts to greatly depend on the mist droplet density as sprayed on the wafer: larger defect counts were observed in wafer areas with more intense misting. However, the values obtained were reproducible between two wafers which were

Table 1. Summary of the added defect counts on each wafer. IF132 is initially clean on bare $\mathrm{Si}$, but shows many defects on PAR-817 and much less on TArF-Pi6-001.

\begin{tabular}{|c|c|c|c|}
\hline & Blank Si & PAR-817 & $\begin{array}{c}\text { TArF-Pi6- } \\
\text { 001 }\end{array}$ \\
\hline IF132 & 30 & 46000 & 200 \\
\hline IF169 & 2800 & $>100000$ & 1500 \\
\hline Water & Not Done & Not Done & $>100000$ \\
\hline
\end{tabular}
sprayed and analyzed. Figure 5 and Table 1 show the wafer maps and the added defect counts, respectively, when both IF132 and IF169 were misted on bare Si wafers, wafers coated with PAR-817, and wafers coated with TArF-Pi6-001. IF132 on bare Si wafers shows few added defects, consistent with good initial fluid cleanliness. In addition, with both liquids there appears to be less interaction with the water-specific immersion resist. These results indicate that a highindex-specific topcoat or resist would be beneficial.

\subsection{PAG Leaching Into High Index Fluids}

The PAG amount that leaches from both resists into water, IF132, and IF169 was determined by puddle soaking directly on the resist surface, and then analyzing the fluids for the PAG anion by LC/MS (after PAG calibration curves were established on the instrument). Resists were spun to a thickness of $150 \mathrm{~nm}$ on HMDS-primed $200 \mathrm{~mm}$ wafers, and 


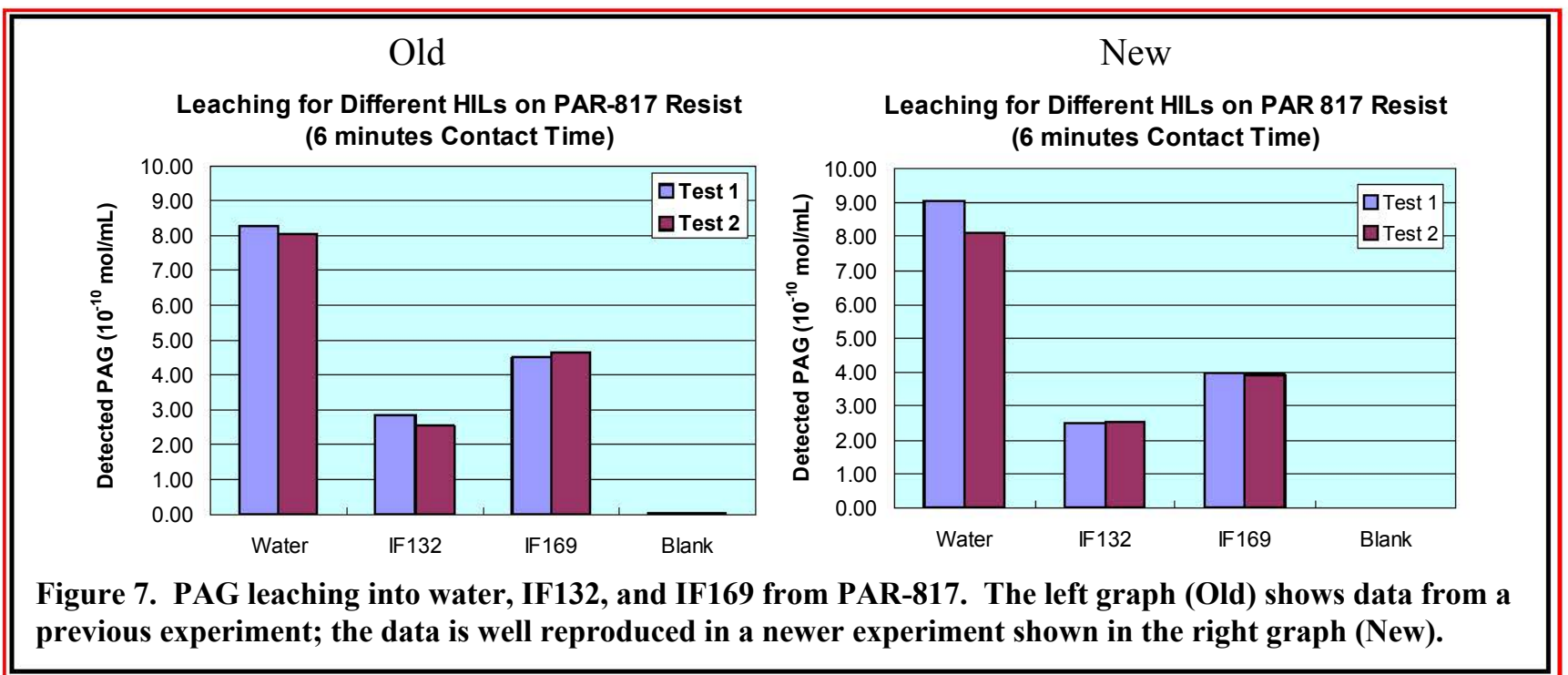

the edges were removed during spinning so that the resist coating diameter was $100 \mathrm{~mm}(\sim 78$ $\mathrm{cm}^{2}$ surface area). After the recommended PEB for each resist, $3 \mathrm{~mL}$ of IF132 or IF169 were puddled over the entire resist area for 6 minutes contact time. The fluids were drained into a glass dish and collected in glass vials for analysis. For water, $15 \mathrm{~mL}$ was used to cover the entire resist surface; so, the results obtained were multiplied by 5 to correct for this volume change. Two wafers were tested for each resist and fluid. Figure 7 shows the leaching data obtained for PAR-817 in two tests over one year apart. The results are reproducible, and show that the least PAG leaching from this resist occurs with IF132. At 6 minutes, PAG leaching is on the order of $3 \times 10^{-10} \mathrm{~mol} / \mathrm{mL}$ (or $3.2 \times 10^{-14}$ $\mathrm{mol} / \mathrm{cm}^{2}$-sec), about two orders of magnitude lower than the upper limit specified by the stepper manufacturers (assuming PAG leaching is linear in time). On TArF-Pi6-001, we could Leaching for different HILs on TARF-Pi6-001 Resist (6 minutes Contact Time)

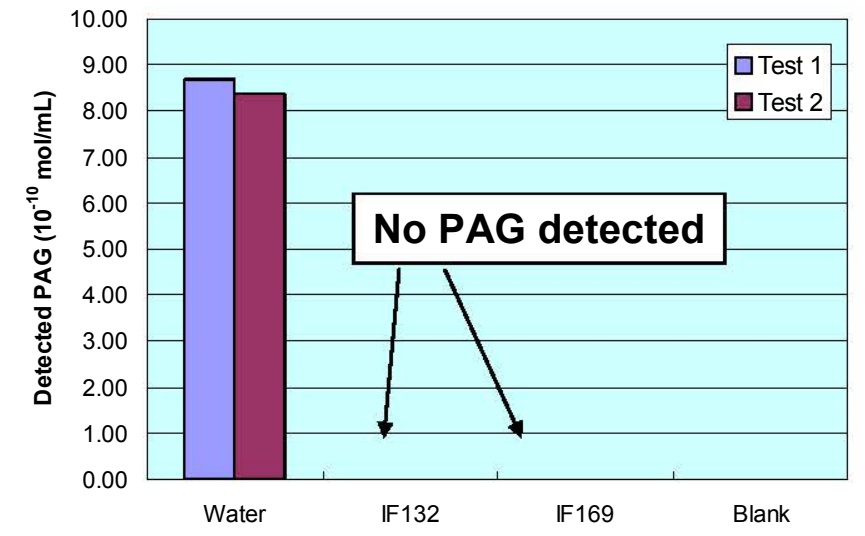

Figure 6. PAG leaching into both high index liquids from TArF-Pi6-001 is negligible. PAG leaching into water is comparable to the leaching seen from PAR-817.

\section{not detect measurable PAG leaching into either}

IF132 or IF169 (Figure 6). PAG leaching from this immersion-specific resist into water is comparable to leaching from PAR-817. The reduced PAG leaching with the immersion-specific resist is also consistent with the wafer defect maps above, since leached PAG is expected to contribute to defects in misted-and-evaporated droplets.

\subsection{Pre- And Post-Soak Imaging}

A resist stack consisting of $77 \mathrm{~nm}$ ARC29A and $150 \mathrm{~nm}$ of either PAR-817 or TArF-Pi6-001 resist was printed with $90 \mathrm{~nm}$ LS patterns on an ASML PAS5500/1100 (0.75 NA, 0.89-0.59 sigma outer-inner illumination). Water, IF132, or IF169 was puddled (30-40 mL for 60 seconds) over the resist and spun off (2000 rpm) during pre- or post-exposure, and average resist profiles were obtained using scatterometry metrology (KLA-T F5) after development. Figure 8 and Figure 9 show the delta change, in nm or degrees, of MCD (middle CD), Rth (resist thickness), and SWA (sidewall angle) of each soaking experiment, compared to dry-wafer experiments for PAR-817 and TArF-Pi6-001. With water, the PAR817 resist profiles became wider and thicker in both pre- and post-exposure soaking. For TArF-Pi6-001, the profiles are more tapered, but there is also less CD and thickness change in pre- and post-exposure soaking. IF132 shows the most interaction in post-exposure soaking mode in both resists: the profiles become thinner in width and height. For IF169, 
there is less CD or thickness change in both resists. Overall, the TArF-Pi6-001 resist shows less profile change for all fluids in both pre- and post-exposure soak modes. These results indicate that, without a topcoat, resists that are designed specifically for immersion imaging, especially with high-index fluids, will be needed.

\section{FLUID LIFECYLE: RADIATION DURABILITY AND ACTIVE RECYCLE}

\subsection{Typical Fluid and Window Radiation Durability Doses}

Radiation durability studies must meaningfully relate to the conditions found in modern lithographic tools. At last year's conference, we reported on the development of the Standard Stepper Tool, whereby experimental radiation durability studies could be properly related to commercial stepper/scanner conditions. In Figure 10 below, the Standard Stepper Tool is shown as the "Stepper Down" Perspective: using typical stepper parameters, and reasonable immersion fluid values, to define doses for both the immersion fluid as well as the final lens element in contact with the fluid ("window"). An alternative approach is the "Wafer Up" Perspective: using typical resist parameters and throughput conditions to define the dose values. These two perspectives are considered to reasonably bracket the conditions which will be encountered in actual practice, which will of course vary among users. As a starting point based on the values shown, we define typical values of $60 \mathrm{~kJ} / \mathrm{cm}^{2}$ for the daily window dose, and $6 \mathrm{~J} / \mathrm{cm}^{2}$ for the weekly fluid dose.
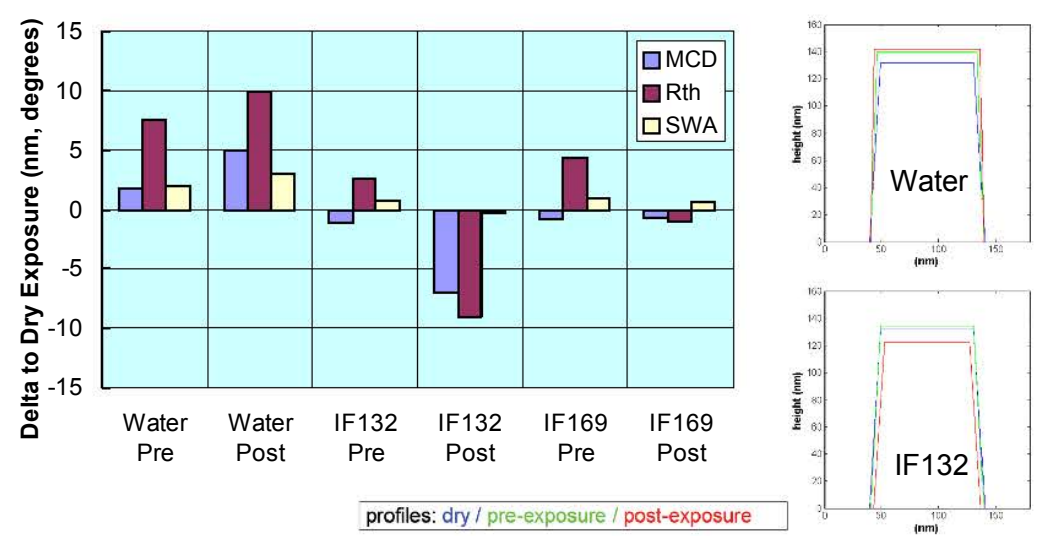

Figure 8. Delta between scatterometry parameters for a dry reference wafer of PAR-817 and wafers soaked pre- or post-exposure in different liquids. $\mathrm{MCD}=$ middle $\mathrm{CD}, \mathrm{Rth}=$ resist thickness, and $\mathrm{SWA}=$ sidewall angle. Profiles are also shown on the right.
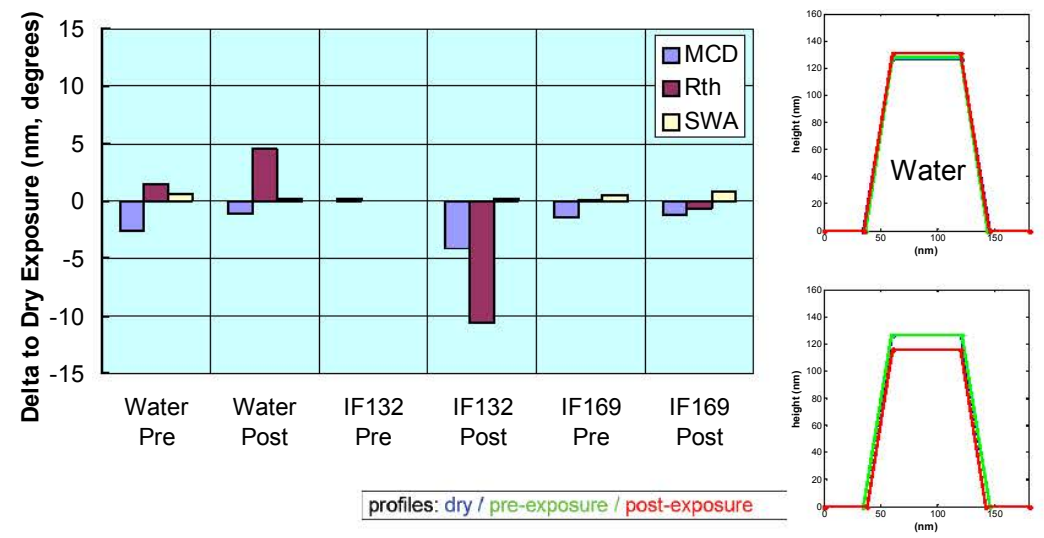

Figure 9. Delta between scatterometry parameters for a dry reference wafer of TArF-Pi6-001 and wafers soaked pre- or post-exposure in different liquids. $\mathrm{MCD}=$ middle $\mathrm{CD}, \mathrm{Rth}=$ resist thickness, and SWA $=$ sidewall angle. Profiles are also shown on the right.

Expose A Day's Wafers: What Is The Delivered Dose?

\begin{tabular}{|c|c|}
\hline "Stepper Down" Perspective & "Wafer Up" Perspective \\
\hline $.6 \mathrm{kHz}, 0.8 \mathrm{~mJ} / \mathrm{cm}^{2} /$ pulse Laser & - For A Resist Sensitivity Of $30 \mathrm{~mJ} / \mathrm{cm}^{2}$ \\
\hline$\cdot 28 \mathrm{~mm} \times 7 \mathrm{~mm}$ Slot, 0.5 Duty Cycle & - 3000 Wafers Per Day \\
\hline$\cdot 1.568 \mathrm{~mJ} /$ pulse & • $300 \mathrm{~mm}$ Wafers \\
\hline - For $3 \mathrm{~mm}$ Fluid Thickness & - For 3mm Fluid Thickness \\
\hline - And 100 liter Reservoir & - And 100 Liter Reservoir \\
\hline Total Daily Laser Dose $=406 \mathrm{~kJ} /$ Day & Total Daily Laser Dose = $64 \mathrm{~kJ} /$ Day \\
\hline Total Window Dose $=207 \mathrm{~kJ} / \mathrm{cm}^{2}$ & Total Window Dose $=34 \mathrm{~kJ} / \mathrm{cm}^{2}$ \\
\hline Fluid Dose Is $1.2 \mathrm{~J} / \mathrm{cm}^{2}$ & Fluid Dose Is $0.2 \mathrm{~J} / \mathrm{cm}^{2}$ \\
\hline
\end{tabular}

"Typical" Estimates
$60 \mathrm{~kJ} / \mathrm{cm}^{2}$ Window Dose Per Day
$6 \mathrm{~J} / \mathrm{cm}^{2}$ Fluid Dose Per Week

Real Values Dependent On Many Factors

- Since Stepper And Lithography Process Are "Owned" By Others

Figure 10. Estimates of typical window and fluid doses from a stepper down and a wafer up perspective. 
4.2 Improvements in Active Recycle: Reducing The Induced Fluid Absorbance Rate

The experimental procedures for determining induced window and fluid absorbance increases ("darkening rates") have been previously reported. Our principal fluid candidate, IF132, has a natural (i.e., in the absence of active recycle) darkening rate of $0.079 \mathrm{~J} / \mathrm{cm}$, determined over many experiments (Figure 11). With early versions of our ARP (Active Recycle Package) technology, this darkening rate could be significantly reduced, with versions 3 and 4 of this technology giving Fluid Lifetime Factors (i.e., darkening rate ratio for no ARP, versus with ARP) in the range of 3-9 (Figure 12).

We continue to optimize this technology, with a version 5 ARP now giving a Fluid Lifetime Factor of 15 (Figure 13). The exact translation of this factor into usable fluid life depends on the upper permissible tool limit of fluid absorbance. However, based on our typical initial fluid absorbances of $0.03 / \mathrm{cm}$, and an assumed upper absorbance limit of $0.10 / \mathrm{cm}$, this result indicates the capability of week long fluid use at acceptable absorbance values.

\subsection{Active Recycle For Suppression Of Window Contamination}

Successful ARP technology must not only suppress fluid degradation, but must also minimize increases in final lens element absorbance due to the fluid-lens contact under $193 \mathrm{~nm}$ illumination. Figure 14 compares the induced window absorption for a version 5.2 ARP versus a no ARP case. In the ARP's absence, window darkening began rapidly, and proceeded at a greater-than-linear rate over the range studied. In contrast, with the ARP, there was an induction (or suppression) period in which no increase in window absorption was seen up to a dose of about $6 \mathrm{~kJ} / \mathrm{cm}^{2}$, and a roughly linear increase thereafter over the range studied. Thus, the ARP clearly reduced window contamination; with an acceptable absorption increase set at $0.005 / \mathrm{cm}$, this corresponds to a few hours of window/lens use before the upper limit is reached. Further studies are underway to increase this value, and there are preliminary indications that at least over a day's use can be achieved.

\section{CONCLUSIONS}

High-index immersion fluid technology continues to show the advances required for its manufacturing insertion. As a selected part of our total studies, we have reported here on aspects of

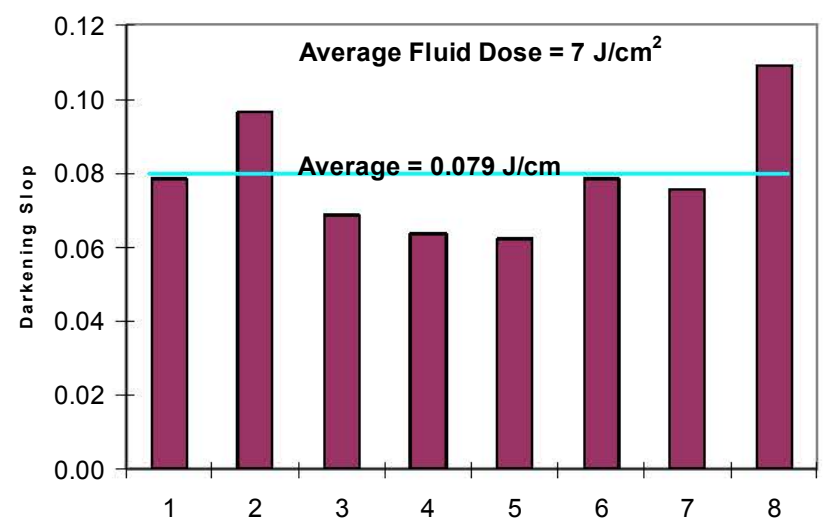

Figure 11. Induced fluid absorbance rate (darkening rate) for IF132 without the use of Active Recycle.

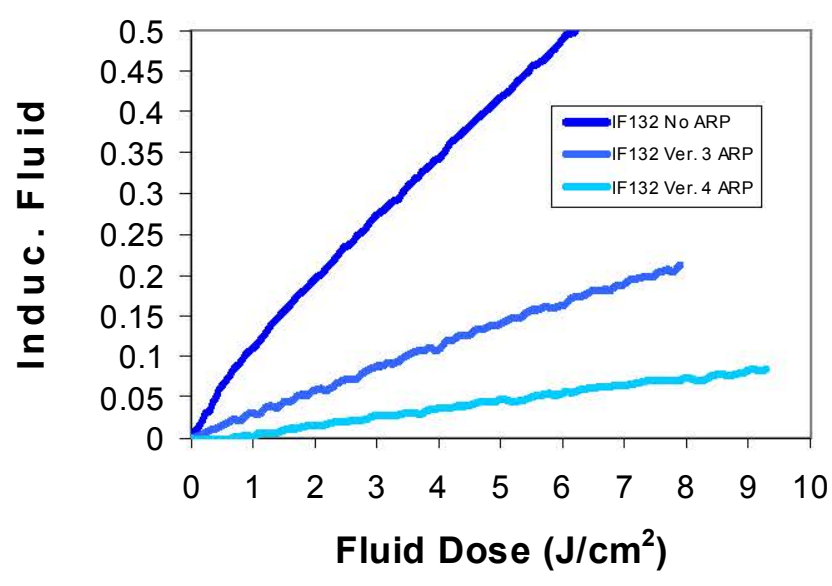

Figure 12. Induced fluid absorbance versus fluid dose for IF132 with No ARP, v3 and v4 ARP.

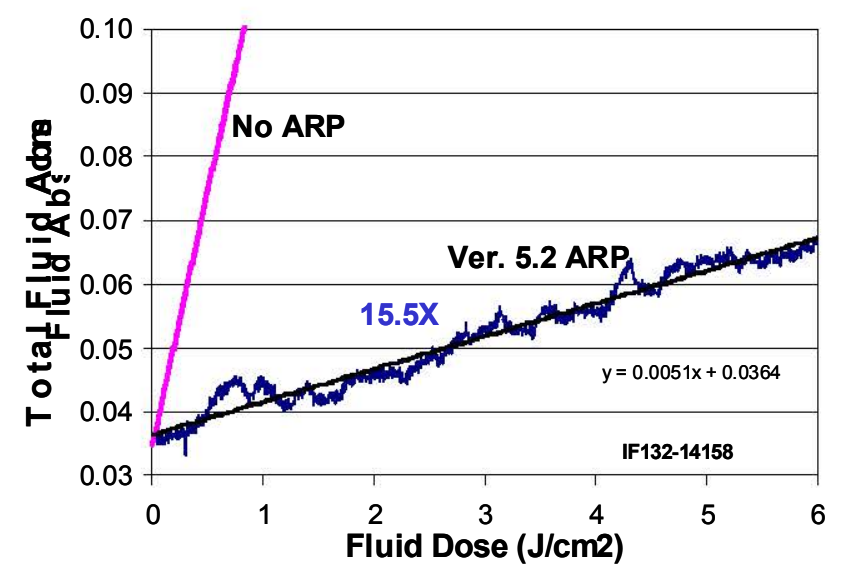

Figure 13. Total fluid absorbance versus fluid dose for IF132 with No ARP and v 5.2 ARP. 
fluid quality, fluid-resist interactions, and fluidrelated radiation durability improvements. Fluid quality in terms of both soluble and insoluble impurities has been analyzed, and fluid-resist interaction studies have revealed issues related to both surface defects and imaging effects. Using immersion-specific resists can greatly reduce potential defects from such contact. Our Active Recycle Package technology leads to enhanced fluid and final lens element useful lifetimes. These are among the advances which will permit high-index immersion lithography to find its appropriate place among the three main approaches to patterning at 32 $\mathrm{nm}$ half-pitch and below: as an approach with greater process latitude and improved throughput/cost versus water-immersion double patterning; and as a method (with double patterning) which can extend towards $16 \mathrm{~nm}$, thus enabling the orderly maturing of the full set of required EUV technologies.

\section{ACKNOWLEDGEMENTS}

The authors would like to acknowledge the assistance of Katsumi Ohmori and Junichi Onodera of TOK in the fluid resist interactions; Vlad Liberman, Keith Krohn and Mordy Rothschild of MIT-Lincoln Labs, Keita Sakai, Yuichi Iwasaki and Shin-ichi Hara of Canon, Harry Sewell, and Jan Mulkens of ASML, Paul Graupner and Ruediger Duesing of Zeiss and Bryan Rice of Sematech in the radiation durability testing.

\section{REFERENCES}

${ }^{1}$ R. H. French, H. Sewell, M. K. Yang, S. Peng, D. McCafferty, W. Qiu, R. C. Wheland, M. F. Lemon, L. Markoya, M. K. Crawford M. K. Crawford, "Imaging Of 32-nm 1:1 Lines And Spaces Using 193-nm Immersion Interference Lithography With Second-Generation Immersion Fluids To Achieve A Numerical Aperture Of 1.5 And A k1 Of 0.25", Journal of Microlithography, Microfabrication and Microsystems, 4(3), 031103-1-14, (2005).

${ }^{2}$ S. Peng, R. H. French, W. Qiu, R. C. Wheland, M. K. Yang, M. F. Lemon, M. K. Crawford, "Second Generation Fluids for 193 nm Immersion Lithography”, Optical Microlithography XVIII, SPIE Vol. ML5754-76, (2005).

${ }^{3}$ R. H. French, M. K. Yang, M. F. Lemon, R. A. Synowicki, G. K. Pribil, G. T. Cooney, C. M. Herzinger, S. E. Green, J. H. Burnett, S. Kaplan, "Immersion Fluid Refractive Indices Using Prism Minimum Deviation Techniques", Optical Microlithography XVII, SPIE Vol. 5377-173, (2004).

${ }^{4}$ R. A. Synowicki, G. K. Pribil, G. Cooney, C. M. Herzinger, S. E. Green, R. H. French, M. K. Yang, J. H. Burnett, S. Kaplan, "Fluid Refractive Index Measurements Using Roughened Surface and Prism Minimum Deviation Techniques" Journal of Vacuum Science And Technology B, 22, 6, 3450-3, (2004).

${ }^{5}$ S. Peng, R. H. French, W. Qiu, R. C. Wheland, M. K. Yang, M. F. Lemon, M. K. Crawford, "Second Generation Fluids for 193 nm Immersion Lithography”, Optical Microlithography XVIII, SPIE Vol. ML5754-76, (2005).

${ }^{6}$ R. H. French, W. Qiu, M. K. Yang, R. C. Wheland, M. F. Lemon, A. L. Shoe, D. J. Adelman, M. K. Crawford, H. V. Tran, J. Feldman, S. J. McLain, S. Peng, "Second Generation Fluids for 193nm Immersion Lithography", Optical Microlithography XIX, SPIE Vol. ML6154-42, (2006).

${ }^{7}$ Hoang V. Tran, Roger H. French, Douglas J. Adelman, Jerald Feldman, Weiming Qiu, Robert C. Wheland, Luke W. Brubaker, Brian E. Fischel, Barbara B. Fones, Michael F. Lemon, Min K. Yang, Osami Nagao, Mureo Kaku, Michael Mocella, and John J. Schmieg. "Evaluation of Next Generation Fluids for ArF Immersion Lithography Beyond Water", Journal of Photopolymer Science and Technology 20(5), (2007), 729-738.

${ }^{8}$ Eric Hendrickx, Sergei Postnikov, Philippe Foubert, Roel Gronheid, ByeongSoo Kim. "Screening of Second Generation High Index Fluids", Advances in Resist Materials and Processing Technology XXIV, SPIE Vol. 6519, 65190A, (2007). 